\title{
LIDAR INVESTIGATIONS OF OZONE IN THE UPPER TROPOSPHERE - LOWER STRATOSPHERE: TECHNIQUE AND RESULTS OF MEASUREMENTS
}

\author{
Oleg A. Romanovskii ${ }^{1,2 *}$, Alexey A. Nevzorov ${ }^{1}$, Alexey V. Nevzorov ${ }^{1}$, Olga V. Kharchenko ${ }^{1}$ \\ ${ }^{1}$ V.E. Zuev Institute of Atmospheric Optics, Tomsk, Russia, *roa@iao.ru \\ ${ }^{2}$ National Research Tomsk State University, Tomsk, Russia
}

\begin{abstract}
The main aim of the research is to develop the technique for laser remote ozone sensing in the upper troposphere - lower stratosphere by differential absorption method for temperature and aerosol correction and analysis of measurement results. The authors have determined wavelengths, promising to measure ozone profiles in the upper troposphere - lower stratosphere. We present the results of DIAL measurements of the vertical ozone distribution at the Siberian lidar station in Tomsk. The recovered ozone profiles were compared with IASI satellite data and Kruger model.
\end{abstract}

\section{INTRODUCTION}

Among techniques for measuring the spatial distribution of the concentration of an atmospheric gas the most sensitive is the differential absorption method (DIAL). Laser sounding of the ozonosphere became routing at some observatories from the second half of 1980s [1-2]. It allows receiving data on vertical distribution of ozone (VDO), which successfully supplement similar data received by contact methods with the use of ozonesondes, rockets, and satellites (TOMS, SAGE-II, TERRA, MetOp, etc.). Laser sounding of the vertical distribution of stratospheric ozone has been carried out at the Siberian Lidar Station (SLS) of Institute of Atmospheric Optics SB RAS (Tomsk, 56.5 ${ }^{\circ} \mathrm{N}$, $85.0^{\circ}$ E) since 1989. A long period of lidar observations of stratospheric ozone has shown that a part of the ozonosphere the most important for the study is located in the lower stratosphere, where ozone is affected by the dynamic factor. The aims of this work are selection of VDO sounding wavelengths, design of ozone lidar, development of algorithm and program for VDO retrieval with temperature and aerosol correction, and analysis of the measurement results, including the comparison between the ozone vertical profiles retrieved from the ground-based DIAL lidar system data and the profiles retrieved from IASI/MetOp data.

\section{SELECTION OF WAVELENGTHS}

Lidar measurements of VDO are carried by DIAL in the UV spectral range 200-370 nm (HartleyHuggins band). In this spectral range, the absorption cross-section $\sigma$ is several times larger than that for wavelengths used in stratospheric measurements (e.g., $\sigma_{299}=4.4 \cdot 10^{-19} \mathrm{~cm}^{2}$ for the wavelength $\lambda_{\text {on }}=299 \mathrm{~nm}$ and $\sigma_{308}=1.4 \cdot 10^{-19}$ $\mathrm{cm}^{2}$ for $\lambda_{\text {on }}=308 \mathrm{~nm}$ ). $\mathrm{KrF}$ laser radiation (248 $\mathrm{nm}$ ) or the fourth harmonic of the Nd:YAG laser $(266 \mathrm{~nm})$ are usually used for measurements of tropospheric ozone, in combination with a technique based on the stimulated Raman scattering (SRS) in $\mathrm{H}_{2}, \mathrm{D}_{2}, \mathrm{CO}_{2}$, and other gases. The most common are hydrogen and deuterium. Table 1 represents possible sets of wavelengths that correspond to the 1st, 2nd, and 3rd Stokes $(C)$ frequencies of SRS conversion in $\mathrm{H}_{2}, \mathrm{D}_{2}$, and $\mathrm{CO}_{2}$.

Table 1. Sets of wavelengths that correspond to Stokes (C) frequencies of $\mathrm{SRS}$ conversion in $\mathrm{H}_{2}, \mathrm{D}_{2}$, and $\mathrm{CO}_{2}$

\begin{tabular}{|c|c|c|c|}
\hline \multirow{3}{*}{$\begin{array}{c}\text { Pumping } \\
\text { radiation }\end{array}$} & \multicolumn{3}{|c|}{$\begin{array}{c}\text { Wavelengths (nm) corresponding } \\
\text { to the Stokes frequencies }(C) \text { of the SRS } \\
\text { conversion }\end{array}$} \\
\cline { 2 - 4 } & in $\mathrm{H}_{2}$ & $\mathrm{In} \mathrm{D}_{2}$ & in $\mathrm{CO}_{2}$ \\
& $\mathrm{C} 1 \mathrm{C} 2$ & $\mathrm{C} 1 \mathrm{C} 2 \mathrm{C} 3$ & $\mathrm{C} 2 \mathrm{C}^{2}$ \\
\hline $\begin{array}{c}\mathrm{Nd}: \mathrm{YAG}, \\
266 \mathrm{~nm} \\
\mathrm{KrF},\end{array}$ & 299341 & 289316 & 287299 \\
$248 \mathrm{~nm}$ & 277313 & 268291319 & \\
\hline
\end{tabular}

Different wavelength combinations are used in practice in different altitude ranges in the troposphere and lower stratosphere [2]. We have estimated possibilities of vertical ozone profile sounding in the upper troposphere-lower stratosphere at the wavelength pair $299 / 341 \mathrm{~nm}$. The calculations have shown that these wavelengths allow the sounding up to about $22 \mathrm{~km}$ and ozone measurements in the 
troposphere. The sounding altitude maximum is determined, first, by the range of signal detection at $\lambda_{\text {on, }}$ which is always shorter than the range of signal detection at $\lambda_{\text {off }}$ due to stronger ozone absorption. In view of this, $\lambda_{\text {on }}=299 \mathrm{~nm}$ is preferable to 277 or $292 \mathrm{~nm}$. In addition, wavelengths of 299 and $341 \mathrm{~nm}$ are implemented in one sounding beam, in contrast to, e.g., the 292/313 nm pair 2 (see Table 2). Thus, the wavelength pair 299/341 nm is of higher information content for VDO measurements in the troposphere-lower stratosphere $\quad(5-22 \quad \mathrm{~km}$ altitude range).

\section{LIDAR FOR SENSING THE VDO IN THE UPPER TROPOSPHERE - LOWER STRATOSPHERE}

The sounding wavelengths selected $(299 / 341 \mathrm{~nm})$ were used in the ozone lidar designed. Its block diagram is shown in Fig. 1. The 4th harmonic $(266 \mathrm{~nm})$ of the fundamental frequency of a Nd:YAG laser (LS-2134UT laser, LOTIS TII company, Minsk) is used as a laser radiation source, which is then SRS converted in hydrogen in the 1st $(299 \mathrm{~nm})$ and 2nd (341 nm) Stokes components.

The recording channel of the lidar is equipped with PMTs (R7207-01) and HAMAMATSU amplifier/discriminators (C3866). The pumping pulse energy at a wavelength of $266 \mathrm{~nm}$ is $60 \mathrm{~mJ}$.

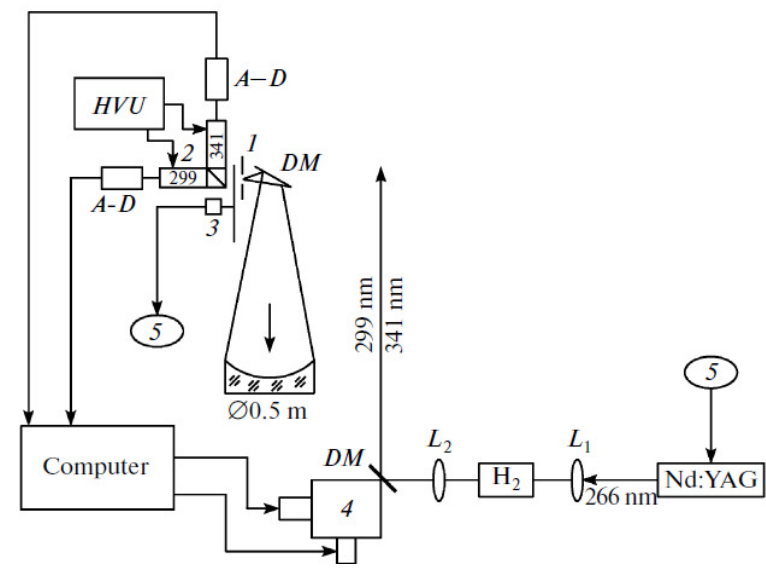

Figure 1 Block-diagram of the lidar: (1) field diaphragm, (2) cell for spectral selection with a PMT, (3) mechanical shutter, (4) automated adjustment unit of the rotating output mirror, (5) system for synchronizing the shutter operation time and the moment of emission of laser pulses, (DM) deflecting mirrors, (Nd:YAG) solid-state laser, (H2) SRS conversion cell with H2, (A-D) amplifiers-discriminators, (HVU) high-voltage power supply units for the PMT, and (L1, L2) lenses

\section{TECNIQUE FOR VDO RETRIEVAL}

Initial equations for calculation of ozone concentration during DIAL lidar sounding of the atmosphere have the form

$$
\begin{aligned}
& N_{o n}(H)=c \cdot\left[\beta_{o n}^{a}(H)+\beta_{o n}^{m}(H)\right] \cdot \exp \left[-2 \int_{0}^{H} \alpha_{o n}^{a}(H)+\alpha_{o n}^{m}+k_{o n} \cdot n(H)\right] \\
& N_{o f f}(H)=c \cdot\left[\beta_{f f}^{a}(H)+\beta_{o f f}^{m}(H)\right] \cdot \exp \left[-2 \int_{0}^{H} \alpha_{o f f}^{a}(H)+\alpha_{o f f}^{m}+k_{o f f} \cdot n(H)\right]
\end{aligned}
$$

where $N(H)$ is the echo-signal recorded at corresponding wavelengths, $C$ is the instrumental constant, $\alpha^{a}$ is the aerosol extinction coefficient, $\beta^{a}$ is the aerosol backscattering coefficient, $k$ is the absorption coefficient, $n(H)$ is the ozone concentration. The final equation is derived with the use of mathematical transformations

$$
\begin{aligned}
& n(H)=\frac{1}{\underbrace{}_{o n}(H, T)-k_{o f f}(H, T)} \\
& \{\underbrace{\frac{d}{d H} \ln \left[\frac{N_{o f}(H)}{N_{o n}(H)}\right]}_{B}-\underbrace{\frac{d}{d H} \ln \left[\frac{\beta_{o f}^{a}(H)+\beta_{o f f}^{m}(H)}{\beta_{o n}^{a}(H)+\beta_{o n}^{m}(H)}\right]}_{C}-\underbrace{2 \cdot\left[\alpha_{o f}^{a}(H)-\alpha_{o n}^{a}(H)\right]}_{D}-\underbrace{2 \cdot\left[\alpha_{o f f}^{m}(H)-\alpha_{o n}^{m}(H)\right]}_{F}\}
\end{aligned}
$$

Actual variations in the air temperature can cause variations in the ozone absorption coefficient, which results in systematic errors in VDO retrieval. Therefore, it is reasonable to carry out a correction to the temperature dependence in the technique and algorithm for VDO retrieval. The model of behavior of ozone absorption crosssections [3, 4], was used in the technique. Transforming the data from $[3,4]$ in a polynomial, we derive equations for calculation of the part $\mathrm{A}$ in Eq. (2):

$$
\begin{gathered}
K_{299}(H, T)-K_{341}(H, T)=5.8815 E-16-1.1538 E- \\
17 \bullet(T(H)-273)+9.0281 E-20 \bullet(T(H)-273)^{2}- \\
3.5194 E-22 \cdot(T(H)-273)^{3}+6.8356 E-25 \bullet(T(H)- \\
273)^{4}-5.2918 E-8 \bullet(T(H)-273)^{5} \quad(3)
\end{gathered}
$$

Aerosol scattering exceeds the molecular one by several times at high atmospheric aerosol content, which significantly distorts ozone profiles retrieved under unconsidered scattering and attenuating properties of the atmosphere. In the considered algorithm for VDO retrieval, the aerosol correction is considered in the equations $C$ and $D$ by means of introduction of a real distribution of the scattering ratio $R_{\text {off }}(H)$, while VDO in the usual, undisturbed atmosphere can be calculated at $R_{\text {off }}(H)=1$. Mathematically transformed equations $C, D$, and $F$ are: 


$$
\begin{gathered}
C=\frac{d}{d H}\left\{\left[\left(\frac{\lambda_{o f f}}{\lambda_{o n}}\right)^{x} \cdot\left[1-\frac{1}{R_{o f f}(H)}\right]+\frac{1}{R_{o f f}(H)} \cdot\left(\frac{\lambda_{o f f}}{\lambda_{o n}}\right)^{4}\right]\right\} \\
D=2 \cdot 0.04 \cdot\left\{\beta_{o f f}^{a}(H) \cdot\left[1-\left(\frac{\lambda_{o f f}}{\lambda_{o n}}\right)^{x}\right]\right\}=2 \cdot 0.04 \cdot\left\{\left[R_{o f f}(H)-1\right] \cdot \beta_{o f f}^{m}(H) \cdot\left[1-\left(\frac{\lambda_{o f f}}{\lambda_{o n}}\right)^{x}\right]\right\} \\
F=2 \cdot 0.119 \cdot \beta_{o f f}^{m}(H) \cdot\left[1-\left(\frac{\lambda_{o f f}}{\lambda_{o n}}\right)^{4}\right], \quad \text { (4) }
\end{gathered}
$$

where, at corresponding wavelengths $\lambda$ (on at an absorption line and off out of the absorption line), $R_{\text {off }}(H)$ is the real distribution of the scattering ratio, $x$ is the parameter that characterizes the particle size, $\beta^{\alpha}{ }_{\text {off }}(H)$ is the aerosol backscattering coefficient, $\beta_{\text {off }}^{m}(H)$ is the molecular backscattering coefficient. The typical errors of the retrieved $\mathrm{O}_{3}$ profiles are in the range from 10 to $25 \%$. To decrease the retrieval errors, the temperature correction of ozone absorption coefficients is used in the software. A high aerosol concentration in the $0-20 \mathrm{~km}$ altitude range should be considered during lidar signal retrieval when sounding at 272/289 nm and 299/341 nm wavelengths; therefore, aerosol correction is considered in the software. The technique and software developed were used for VDO retrieval in the upper stratosphere - lower stratosphere at 299/341 nm wavelengths.

\section{MEASUREMENT RESULTS}

VDO profiles retrieved from lidar sounding data are compared with the IASI/MetOp measured profiles. The IASI is mounted onboard the European Space Agency meteorological satellite MetOp. IASI provides for spectra of high radiometric quality with a resolution of $0.5 \mathrm{~cm}^{-1}$ in the range from 625 to $2760 \mathrm{~cm}^{-1}$ [5]. The ozone profiles were retrieved from satellite sounding data in the range $1025-1075 \mathrm{~cm}^{-1}$. The range of lidar signal detection was from 5 to $18 \mathrm{~km}$. The ozone vertical profile error was from 6 to $18 \%$. The coordinates and time of the lidar and satellite sounding are given in Table 2 .

Figure 2 exemplifies the comparison of lidar and satellite vertical profiles of ozone measured on April 26, 2015; the VDO profiles are compared with the Krueger model [6]. All ozone measurements are shown by three curves: the retrieved lidar profile, IASI profile, and Krueger model. Figure 2 shows that the profiles retrieved from lidar and satellite data agree quite well throughout the layer of measurements. The lidar profile mainly repeats the form of the IASI curve, even with overestimated lidar data near 9 and 13 $\mathrm{km}$. Above $7 \mathrm{~km}$ height, the measured profiles differ from the model profile, which is natural for the ozone dynamics at certain days of measurements.

Table 2. Coordinates and time of satellite and lidar sounding

\begin{tabular}{|c|c|c|c|c|}
\hline \multirow{2}{*}{ Date } & \multicolumn{2}{|c|}{ Siberian Lidar Station } & \multicolumn{2}{c|}{ MetOp (IASI) satellite } \\
\cline { 2 - 5 } & $\begin{array}{c}\text { Greenwich } \\
\text { time }\end{array}$ & $\begin{array}{c}\text { Coordinates } \\
(56.5 \mathrm{~N}, \\
85.0 \mathrm{E})\end{array}$ & $\begin{array}{c}\text { Greenwich } \\
\text { time }\end{array}$ & Coordinates \\
\hline 13.01 .2015 & $11: 53-13: 45$ & $14: 17$ & $\begin{array}{c}56.472 \mathrm{~N}, \\
85.387 \mathrm{E}\end{array}$ \\
\hline 19.02 .2015 & $12: 39-14: 13$ & $14: 53$ & $\begin{array}{c}56.681 \mathrm{~N}, \\
85.164 \mathrm{E}\end{array}$ \\
\hline 05.03 .2015 & $13: 05-14: 56$ & $15: 02$ & $\begin{array}{c}56.472 \mathrm{~N}, \\
85.118 \mathrm{E}\end{array}$ \\
\hline 20.03 .2015 & $13: 32-15: 24$ & $14: 53$ & $\begin{array}{c}56.691 \mathrm{~N}, \\
85.124 \mathrm{E}\end{array}$ \\
\hline 06.04 .2015 & $14: 25-16: 17$ & $15: 41$ & $\begin{array}{c}56.254 \mathrm{~N}, \\
84.935 \mathrm{E}\end{array}$ \\
\hline 26.04 .2015 & $15: 11-17: 03$ & $15: 26$ & $\begin{array}{c}56.585 \mathrm{~N}, \\
84.594 \mathrm{E}\end{array}$ \\
\hline
\end{tabular}

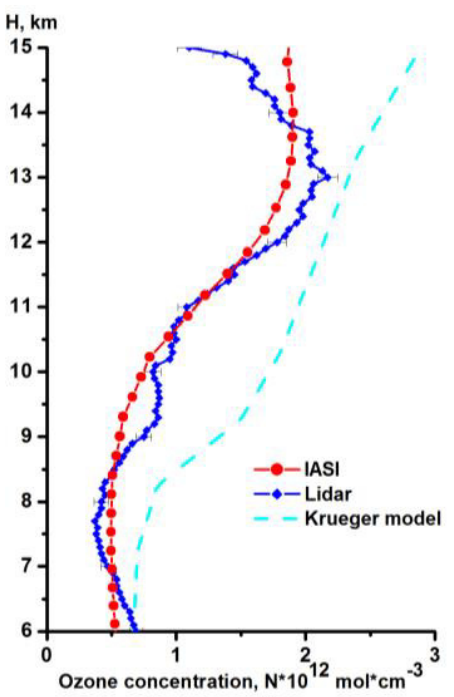

Figure 2 Comparison of vertical profiles of ozone retrieved from lidar and satellite data for April 26, 2015

It should be noted that the lidar operates in the photon counting mode at a spatial resolution of $100 \mathrm{~m}$, while the IASI profile has a more dynamic step of $150 \pm 100 \mathrm{~m}$, which connected with the ozone profile retrieval algorithm of this interferometer [7]. Figure 3 shows all the considered cases of comparison of ozone profiles measured at the SLS and retrieved from IASI data (see Table 2). The measurements are reduced to the total altitude range $6-15 \mathrm{~km}$ for convenience. Increased ozone concentrations measured at the SLS as compared to IASI are seen in the range from 8.5 to $12.5 \mathrm{~km}$ throughout the whole observation period. 


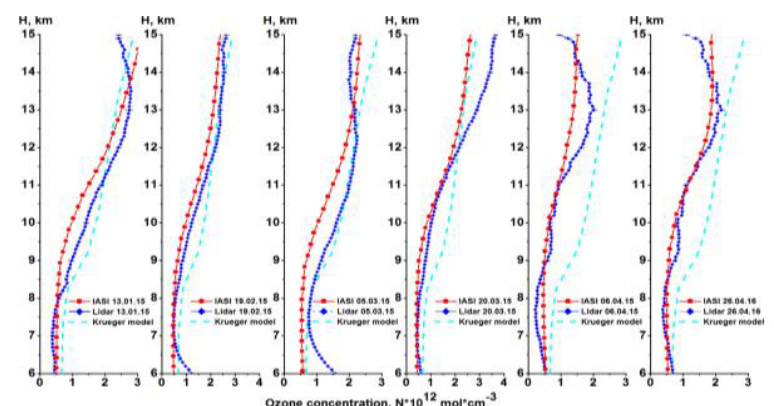

Figure 3 Comparison of vertical profiles of ozone

The following conclusions can be drawn from the analysis of the ozone profiles average over the period under study (Fig. 4). The difference between the lidar and IASI profiles of the ozone concentration growth with altitude. Ozone shows pronounced annual variations; therefore, to find relative errors of its measurements with IASI, the difference in the concentrations was normalized to the lidar data: (Lidar - IASI)/Lidar. These data are shown in Fig. 4c; it is seen that the mean relative difference is positive in the altitude ranges 6-6.4 and $8.4-15 \mathrm{~km}$ and attains $80.07 \%$ at an altitude of $13.7 \mathrm{~km}$.

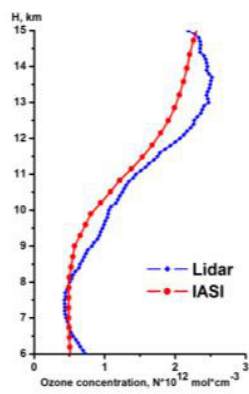

a

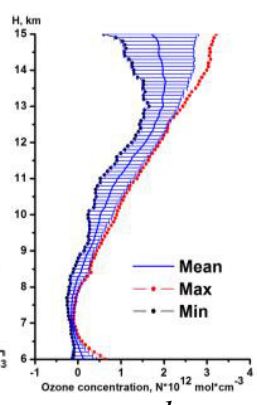

b

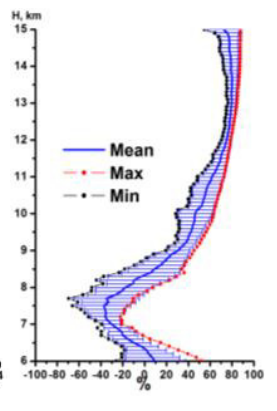

$c$
Figure 4 Mean vertical profiles of ozone (a), their difference (Lidar - IASI) in abs. units (b), and the relative difference (Lidar - IASI)/lidar (c)

The comparison performed shows that the absolute differences in the lidar and IASI measured ozone concentrations can change from 0.25 to $3.21 * 10^{12} \mathrm{~mol} . \mathrm{cm}^{-3}$.

\section{CONCLUSIONS}

The results of use of the developed techniques for VDO DIAL retrieval with temperature and aerosol correction confirm prospects of the wavelengths chosen (299 and $341 \mathrm{~nm}$ ) for ozone lidar sounding. Results of lidar measurements at 299 and $341 \mathrm{~nm}$ agree with model estimates, which point out to acceptable accuracy of ozone sounding in altitudes near 6-18 km.

\section{ACKNOWLEDGEMENTS}

The work was supported by the Russian Science Foundation (Agreement No. 15-17-10001).

\section{References}

[1] Bukreev V.S., Vartapetov S.K., Veselovskii I.A., Shablin Yu.S., 1996: Excimer-laser-based lidar system for stratospheric and tropospheric ozone measurements, Quantum Electron., 26(6), 546-551.

[2] Eisele H., Scheel H.E., Sladkovic R., Trickl T., 1999: High resolution lidar measurements of stratosphere - troposphere exchange, J. Atmos. Sci., 56(3), 319-330.

[3] Malicet J., Daumont D., Charbonnier J., Parisse C., Chakir A., Brion J., 1995; Ozone UV spectroscopy. II. Absorption cross-sections and temperature dependence, J. Atmos. Chem., 21(3), 263-273.

[4] Zhu H., Qu Z.W., Grebenshchikov S.Y., Schinke R., Malicet J., Brion J., Daumont D., 2005; Huggins band of ozone: Assignment of hot bands, J. Chem. Physics., 122(2), Article Number 024310.

[5] Clerbaux C., Boynard A., Clarisse L., George M., Hadji-Lazaro J., Herbin H., Hurtmans D., Pommier M., Razavi A., Turquety S., Wespes C., and Coheur P.-F., 2009: Monitoring of atmospheric composition using the thermal infrared IASI/MetOp sounder, Atmos. Chem. Phys., 9(16), 6041-6054.

[6] Krueger A.J., Minzner R.A., 1976: Mid-latitude ozone model for the 1976 U.S. Standard Atmosphere, J. Geophys. Res., 81(D24) 44774488.

[7] August T., Klaes D., Schlüssel P., Hultberg T., Crapeau M., Arriaga A., O'Carroll A., Coppens D., Munro R., Calbet X., 2012: IASI on MetopA: Operational Level 2 retrievals after five years in orbit, J. Quant. Spectrosc. and Radiat. Transfer. 113(11), 1340-1371. 